\title{
The kinetics of nucleation of solid solutions from aqueous solutions: A new model for calculating non-equilibrium distribution coefficients.
}

\author{
C. M. PInA, * and A. PUTNIS \\ Institut für Mineralogie. Universität Münster. Corrensstraße 24. D-48149. Germany.
}

(Received November 8, 2000; accepted in revised form June 20, 2001)

\begin{abstract}
The nucleation kinetics of binary solid solutions, with general formula $\mathrm{B}_{\mathrm{x}} \mathrm{C}_{1-\mathrm{x}} \mathrm{A}$, crystallising from aqueous solution can be described using a generalised expression for the nucleation rate: the function, $J(x)$, in which supersaturation, interfacial free energy and other parameters of the classical nucleation rate equation are considered as functions of the solid composition. As an example, we studied the behaviour of such $J(x)$ functions for the case of the $(\mathrm{Ba}, \mathrm{Sr}) \mathrm{SO}_{4}$ and $(\mathrm{Ba}, \mathrm{Sr}) \mathrm{CO}_{3}$ solid solutions. $J(x)$ functions are very sensitive to slight changes in the composition of the aqueous solution, which result in strong modifications of the nucleation kinetics. The implications of the relationship between supersaturation and nucleation rate functions for the general nucleation behaviour in solid solution-aqueous solution (SS-AS) systems are discussed. Finally, we present a method for constructing non-equilibrium Roozeboom diagrams based on the nucleation kinetics in SS-AS systems. Our Roozeboom diagrams calculated for different departures from equilibrium conditions are consistent with previous experimental work and they can be used to predict actual distribution coefficients.
\end{abstract}

\section{INTRODUCTION}

Nucleation is the first step leading to the formation of crystals from supersaturated aqueous solutions. One of the most important aspects of the nucleation process is the kinetics of nuclei formation within a solution under given conditions. Nucleation kinetics has been traditionally described by the nucleation rate equation, which relates the number of nuclei formed per unit of volume and time to supersaturation, interfacial free energy, solubility and other basic parameters (Nielsen, 1964; Walton, 1969). Nucleation rate data provide information about the metastability and physicochemical properties of solutions and many experimental and theoretical works have been devoted to evaluating the relationship between nucleation parameters in the nucleation rate equation and the kinetics of nuclei formation (Sangwal, 1989; Söhnel, 1982). Conversely, experiments conducted to determine the width of the metastable zone in solute-solvent systems allow the determination of interfacial energies and related thermodynamic constants, such as dissolution enthalpies or surface entropies, for a wide number of inorganic and organic substances (Sangwal, 1989; Nielsen and Söhnel, 1971).

Most experiments on nucleation kinetics are carried out in single solute-solvent systems and only occasionally small amounts of other solutes, generally considered as impurities, are added. In such cases the observed changes in nucleation kinetics are not interpreted in terms of the modification of the parameters in the nucleation rate equation but as a consequence of the incorporation of "impurities" in the nuclei. However, in many natural and industrial crystallisation processes nucleation occurs from multicomponent solutions and the solid formed exhibits a wide compositional variability, i.e., a solid solution. It is clear that, in such a situation, the processes involved in the

* Author to whom correspondence should be addressed (pina@nwz.uni-muenster.de). incorporation of isomorphic growth units to the initial nuclei will play a decisive role in the nucleation behaviour. Therefore, to understand nucleation kinetics in multicomponent crystallisation systems, the application of the nucleation rate equation must be done taking into account the physicochemical properties of the solid solution-aqueous solution (SS-AS) system, i.e., solid-aqueous phase equilibrium, supersaturation state, ionic mobility, etc.

Here we present a generalisation of the nucleation rate equation for the crystallisation of binary solid solutions from aqueous solutions. We considered that some basic parameters in this equation, such as supersaturation, interfacial free energy and molecular volume are not constant, but functions of both the solid and aqueous phase compositions and of the solid solution solubility. The generalised $J(x)$ equation has been applied to the case of the $(\mathrm{Ba}, \mathrm{Sr}) \mathrm{CO}_{3}$ and $(\mathrm{Ba}, \mathrm{Sr}) \mathrm{SO}_{4}$ solid solutions. The end members in the former solid solution have very similar solubility products, while those in the latter have very different solubility products. We have calculated the $(\mathrm{Ba}, \mathrm{Sr}) \mathrm{CO}_{3}$ and $(\mathrm{Ba}, \mathrm{Sr}) \mathrm{SO}_{4}$ solid solution compositions for which the nucleation rate reaches a maximum, at varying degrees of supersaturation with $\mathrm{Ba} / \mathrm{Sr}$ ionic ratios ranging from 0 to 1 . By plotting the composition of each starting aqueous solution against the composition of the solid for which $J(x)$ is a maximum we can construct kinetic Roozeboom diagrams, which reflect the effect of the nucleation kinetics on the distribution coefficients between aqueous and solid phases. We have calculated Roozeboom diagrams for $(\mathrm{Ba}, \mathrm{Sr}) \mathrm{CO}_{3}-\mathrm{H}_{2} \mathrm{O}, \mathrm{Ba}\left(\mathrm{SO}_{4}, \mathrm{CrO}_{4}\right)-\mathrm{H}_{2} \mathrm{O}$, (Ba, $\mathrm{Sr}) \mathrm{SO}_{4}-\mathrm{H}_{2} \mathrm{O}$ and $(\mathrm{Cd}, \mathrm{Ca}) \mathrm{CO}_{3}-\mathrm{H}_{2} \mathrm{O}$ sytems. Our calculations are in good agreement with the experimental findings reported by Prieto et al., 1997 for the same conditions of supersaturation and aqueous solution compositions. Therefore, our theoretical diagrams can be used, in principle, to predict the nucleation behaviour in any SS-AS system at far from equilibrium conditions. 


\section{THEORY}

\subsection{The Nucleation Rate Function, $J(x)$}

In the classical homogeneous nucleation theory, the rate of nucleation, i.e., the mumber of nuclei formed per unit of volume and ime is given by the expression:

$$
J=\Gamma \cdot \exp \left[\frac{-B \sigma^{3} \Omega^{2}}{k^{3} T^{3}(\ln S)^{2}}\right]
$$

where $B$ is a shape factor equal to $16 \pi / 3$ for a spherical nucleus and equal to 32 for a cubic nucleus; $\sigma$ is the interfacial free energy; $\Omega$, the molecular volume, $k$, the Boltmann constant $\left(1.38 \times 10^{-23} \mathrm{~J} / \mathrm{K}\right) ; T$, the absolute temperature and $S$, the supersaturation ratio: $S=C / C_{s}$, where $C_{s}$ is the concentration of the solution in equilibrium with the crystalline phase (i.e., solubility) and $C$ is the actual concentration of the solution. Finally, $\Gamma$ is a preexponential factor related to solubility and which includes a volume diffusion step, i.e., an energy barrier for the incorporation of growth units from the solution bulk to the critical nucleus must be overcome.

From inspection of the parameters in Eqn. 1 it is clear that supersaturation, interfacial free energy and the preexponential factor are the main factors controlling nucleation kinetics. In addition, $S$ and $\sigma$ play an opposite role in this equation: the nucleation rate increases when the supersaturation increases and it decreases with increasing interfacial free energy (and decreasing solubility).

The situation is not so simple when we deal with crystallisaton in SS-AS systems. In such a case, under given temperature and solution composition conditions, the main controlling factors in the nucleation rate equation, $S, \sigma, \Omega$ and $\Gamma$, are not single parameters, but they depend on the solid composition. This means that any composition of the aqueous solution will have a different supersaturation relative to each possible composiion of the solid solution, which in turn will have a different interfacial energy and $\Gamma$ value. In other words, the nucleation rate is a function of the solid solution composition and Eqn. 1 must be rewritten as:

$$
J(x)=\Gamma(x) \exp \left[\frac{-B \sigma^{3}(x) \Omega^{2}(x)}{k^{3} T^{3}(\ln S(x))^{2}}\right]
$$

where, $S(x), \sigma(x), \Omega(x)$ and $\Gamma(x)$ are now functions of the solid composition. In the following sections we will analyse in detail the dependence of the $S(x), \sigma(x), \Omega(x)$ and $\Gamma(\mathrm{x})$ on the solid composition and solubility product of the endmembers.

\subsection{The Supersaturation Function, $S(x)$}

The general expression for calculating the supersaturation of a multicomponent aqueous solution with respect to a nonstoichiomeric solid solution is (Prieto et al., 1994; Pumis et al., 1995):

$$
S=\left(\frac{\Pi a_{j}^{v i}}{K_{s}}\right)^{1 / v}
$$

where $\Pi \boldsymbol{a}_{i}^{v i}$ is the ionic activity product, $\nu i$ is the stoichiometric number of ion $i$ in the solute formula, $v=\Sigma v i$ and $K_{s}$ is the solubility product, i.e., the aqueous ion activity product at equilibrium. By applying this expression to a binary solid solution with general formula $\mathrm{B}_{\mathrm{x}} \mathrm{C}_{1-\mathrm{x}} \mathrm{A}$, and by taking into account the Lippmann and Debye-Hückel methods (extensively described in Glym and Reardon, 1990 and in Prieto et al. 1988, 1991) we can derive the supersaturation fumction:

$$
S(x)=\sqrt{\frac{\boldsymbol{a}\left(C^{+}\right)^{1-x} \boldsymbol{a}\left(B^{+}\right)^{x} \boldsymbol{a}\left(A^{-}\right)}{\left(K_{C A} \boldsymbol{a}_{C A}\right)^{1-x}\left(K_{\boldsymbol{B} A} \boldsymbol{a}_{\boldsymbol{B} A}\right)^{x}}}
$$

where $K_{C A}$ and $K_{B A}$ are the solubility products of the endmembers, $\boldsymbol{a}_{C A}$ and $\boldsymbol{a}_{B A}$ the activities of the $C A$ and $B A$ components in the solid solution, respectively and $x=X_{B A}$ and $1-x=X_{C A}$. The shape of the $S(x)$ curve depends on the particular values for $K_{C A}$ and $K_{B A}$ and on the composition of the given aqueous solution (ratio between $C^{+}, B^{+}$and $A-$ ).

\subsection{The Interfacial Free Energy Function, $\sigma(x)$}

Many experimental studies have demonstrated that the interfacial free energy is closely related to the solubility: compounds with lower solubility products have a higher interfacial free energy (Sangwal, 1989; Söhnel, 1982 and Christoffersen et al., 1991). Within an ideal solid solution we will assume, as a first approximation, that the interfacial free energy increases linearly from the more soluble endmember to the less soluble. Therefore, the interfacial free energy can be expressed as a fumction of the solid solution composition with the form:

$$
\sigma(x)=\sigma_{B A}+\left(\sigma_{B A}-\sigma_{C A}\right) X_{C A}
$$

$\sigma_{B A}$ and $\sigma_{C A}$ are the interfacial free energies for the endmembers of the $\mathrm{B}_{\mathrm{x}} \mathrm{C}_{1-\mathrm{x}} \mathrm{A}$ solid solution.

\subsection{The Preexponential Factor, $\Gamma(x)$}

The so-called preexponential factor, $\Gamma$, in the nucleation rate Eqn. 1 is, in fact, a complex fumction, whose complete expression 1s:

$$
\Gamma=N_{\mathbf{\imath}} 4 \pi\left(r^{*}\right)^{2} \frac{k T}{h} \exp \left(-\frac{\Delta G_{v, d i f f}}{k T}\right)
$$

where $N_{0}$ is the number of solute molecules per unit volume of solution (related to the solubility); $4 \pi\left(r^{*}\right)^{2}$ the surface area of the critical nucleus assumed to be spherical; $k T / h$ is a frequency factor and $\Delta G_{v, \text { aliff }}$ is the energy barrier encountered by the solute for volume diffusion from the bulk solution to the nucleus.

The determination of $\Gamma$ is not rivial and the influence of some factors, such as the solvation and ransport processes within the solution, is not well known. Most attempts at calculating $\Gamma$ for inorganic and organic compounds indicate, that such a factor generally lies in the range of $10^{33 \pm 3} \mathrm{~cm}^{-3} \mathrm{~s}^{-1}$. As a good approximation for pure ionic substances (Nielsen, 1964) and assuming isothermal conditions, the parameter $\Gamma$ can be considered constant and for room temperature approximately equal to:

$$
\Gamma=\frac{D}{\Omega^{5 / 3}}
$$

where $\mathrm{D} \approx 10^{-9} \mathrm{~m}^{2} \mathrm{~s}^{-1}$ is the mean diffusion coefficient for the ions in water. 
Obviously, as in the case of the interfacial free energy, the factor $\Gamma$ varies with the composition of the solid when a complete solid solution is considered. As an approximation, the $\Gamma(\mathrm{x})$ fumction can be written as:

$$
\Gamma(x)=\frac{D}{\Omega^{\frac{5}{3}}(x)}
$$

\section{THE NUCLEATION BEHAVIOUR OF THE (Ba,Sr)SO $-\mathrm{H}_{2} \mathrm{O}$ AND $(\mathrm{Ba}, \mathrm{Sr}) \mathrm{CO}_{3}-\mathrm{H}_{2} \mathrm{O}$ SS-AS SYSTEMS}

\subsection{Supersaturation and Nucleation Rate Functions}

To study the general behaviour of the nucleation rate in SS-AS systems we have applied Eqn. 2 and Eqn. 4 to two SS-AS systems: (Ba,Sr)S $\boldsymbol{O}_{4}-\mathrm{H}_{2}$ and $(\mathbf{B a}, \mathrm{Sr}) \mathrm{CO}_{3}-\mathrm{H}_{2} \mathbf{O}$. The solid solutions which crystallise within these systems have been assumed to be complete and ideal (the slight deviation from ideality for $(\mathrm{Ba}, \mathrm{Sr}) \mathrm{SO}_{4}$ reported by Hanor, 1968; Malinin and Urusov, 1983 and Becker et al., 2000 does not significantly affect our results). This assumption allows us to use molar fractions instead of activity fractions for the solid phase, simplifying the calculation of $S(x)$, which otherwise would require regular or subregular solid solution models to evaluate $\boldsymbol{a}_{C A}$ and $\boldsymbol{a}_{B A}$. In addition, these two solid solutions show very different solubilities between the endmembers. This allows us to demons rate the influence of this parameter on the nucleation behaviour. For the $(\mathrm{Ba}, \mathrm{Sr}) \mathrm{SO}_{4}$ solid solution the solubility products of barite $\left(\mathrm{BaS}_{4}\right)$ and celestite $\left(\mathrm{SrS}_{4}\right)$ are very different, whereas the solubility for witherite $\left(\mathrm{BaCO}_{3}\right)$ and strontianite $\left(\mathrm{SrCO}_{3}\right)$ are quite similar. Because the solubility is related to the interfacial free energy, for the case of the $(\mathrm{Ba}, \mathrm{Sr}) \mathrm{SO}_{4}$ solid solution, the difference in the interfacial free energies of the endmembers is also higher than for the endmembers of the $(\mathrm{Ba}, \mathrm{Sr}) \mathrm{CO}_{3}$ solid solution. As we will see such differences are reflected in completely different nucleation kinetics.

Before obtaining the $J(x)$ fumction for a given aqueous soluion composition it is necessary to calculate the corresponding supersaturation fumction using Eqn. 4. Figures la and $1 \mathrm{~b}$ show the $S(x)$ functions calculated for aqueous solutions with equimolar concentrations of $\mathrm{Sr}^{2+}, \mathrm{SO}_{4}^{2-}$ (or $\mathrm{CO}_{3}^{2-}$ ) and minor $\mathrm{Ba}^{2+}$ (see figure caption), as a function of the solid solution compositions ( $\mathrm{Ba}, \mathrm{Sr}) \mathrm{S}_{4}$ and $(\mathrm{Ba}, \mathrm{Sr}) \mathrm{C}_{3}$ respectively. As can be seen in Figure 1a, the supersaturation function for the $(\mathrm{Ba}, \mathrm{Sr}) \mathrm{SO}_{4}$ aqueous solution has values ranging from approximately 20 to 35 and reaches a maximum for the solid composition $\mathrm{X}_{\mathrm{BaSO} 4}=0.7$. For the $(\mathrm{Ba}, \mathrm{Sr}) \mathrm{SO}_{4}$ solid solution the solubility product of the $\mathrm{BaSO}_{4}$ endmember $\left(K_{s}=10^{-9.98}\right)$ is three orders of magnitude lower than for $\mathrm{SrSO}_{4}\left(K_{s}=10^{-6.63}\right)$. Thus, even though the aqueous $\mathrm{Ba}^{2+}$ concentration is relatively small, the solution is nevertheless moderately supersaturated with respect to the whole range of solid compositions. It also explains the displacement of the supersaturation maximum toward Ba-rich solid solution compositions.

The situation for the $(\mathrm{Ba}, \mathrm{Sr}) \mathrm{CO}_{3}$ solid solution is quite different: $S(x)$ ranges from 6 to 430 and the maximum corresponds to the pure $\mathrm{SrCO}_{3}$ composition. In this case the solubility products of the endmembers $\left(K_{s}=10^{-9.27}\right.$ for $\mathrm{SrCO}_{3}$ and $K_{s}=10^{-\mathbf{8 . 5 6}}$ for $\mathrm{BaCO}_{3}$ ) are similar and the maximum supersaturation of the solution usually corresponds to the end mem- ber composition which is most concentrated in the solution. However, for some aqueous solutions the supersaturation maximum does not coincide with the most concentrated endmember in the solution but it is displaced toward the less soluble one (i.e., $\mathrm{SrC}_{3}$ ). Since the difference in solubility between the endmembers in the $(\mathrm{Ba}, \mathrm{Sr}) \mathrm{CO}_{3}$ solid solution is not very great such a displacement is always smaller than for the case of $(\mathrm{Ba}, \mathrm{Sr}) \mathrm{SO}_{4}$

Once the supersaturation functions have been determined for aqueous solutions of a given composition, the nucleation rate fumctions can be obtained using Eqn. 2. The parameters of the endmembers used for the calculation (interfacial free energy, molecular volume, preexponential factor and solubility product) are listed in Table 1. Figures $1 \mathrm{c}$ and $1 \mathbf{d}$ show the $J(x)$ curves for the previously described solutions. As can be seen, for the case of the $(\mathrm{Ba}, \mathrm{Sr}) \mathrm{CO}_{3}$ the supersaturation and nucleation rate maxima correspond to the same solid composition (pure $\mathrm{SrCO}_{3}$ ), while for the $(\mathrm{Ba}, \mathrm{Sr}) \mathrm{SO}_{4}$ solid solution the nucleation rate maximum is located at a solid composition of $\mathrm{X}_{\mathrm{BaSO} 4}=0.1$, i.e., strongly displaced to the Sr-rich region. This means that in this latter case, the compositions close to celestite are kinetically favoured and the formation of Sr-rich nuclei from a solution of composition $\boldsymbol{a}\left(\mathrm{Sr}^{2+}\right)=\boldsymbol{a}\left(\mathrm{SO}_{4}^{2-}\right)=$ $0.01 \mathrm{~mol} / \mathrm{L}$ and $\boldsymbol{a}\left(B \boldsymbol{a}^{2+}\right)=0.00001 \mathrm{~mol} / \mathrm{L}$ can be expected. As we will see in the next section, where complete ranges of aqueous solution compositions will be considered, differences in nucleation kinetics can lead to important deviations in the distribution coefficient between solid and aqueous phases.

\subsection{Kinetic Roozeboom Diagrams}

If we calculate the nucleation rate fumctions for a complete range of aqueous solutions in which the $\mathrm{Ba}^{2+} / \mathrm{Sr}^{2+}$ ionic ratio ranges from 0 to 1 we obtain a family of curves. Figures $2 \mathrm{a}$ and $\mathrm{b}$ show two examples of $J(x)$ curves for $\mathrm{Ba}^{2+}-\mathrm{Sr}^{2+}-\mathrm{SO}_{4}^{2-}-\mathrm{H}_{2}$ and $\mathrm{Ba}^{2+}-\mathrm{Sr}^{2+}-\mathrm{CO}_{3}^{2-}-\mathrm{H}_{2}-$ systems, respectively. For each curve the solid composition for which the $J(x)$ fumction reaches a maximum represents the most kinetically favoured compositon, i.e., the solid solution composition that will precipitate first. We can then plot the activity fractions of the starting solutions against the solid solution composition for which the nucleation rate is a maximum. Such a plot is a Roozeboom diagram, which contains kinetic information about the nucleation process. Roozeboom diagrams at equilibrium, which can be used as a reference, are given by the general expression:

$$
X_{B A}=\frac{K_{C A} \cdot X_{B, a q}}{\left[\left(K_{C A}-K_{B A}\right) \cdot X_{B, a q}+K_{B A}\right]}
$$

where $\mathrm{X}_{B A}$ is the molar fraction of the $B A$ component in the solid solution and $\mathrm{X}_{\boldsymbol{B} \text {,aq }}$ the molar fraction of the ion $B$ in the aqueous solution.

By varying the supersaturation fumction values (by changing the concentration of the ions in solution but keeping the $\mathrm{Ba}^{2+}$ $\mathrm{Sr}^{2+}$ ratios constant) we can explore the effect of the nonequilibrium on the SS-AS distribution coefficients.

Figure 3a. shows a kinetic Roozeboom diagram for the $\mathrm{Ba}^{2+}-\mathrm{Sr}^{2+}-\mathrm{SO}_{4}^{2-}-\mathrm{H}_{2} \bigcirc$ system. For conditions relatively close to equilibrium (maximum supersaturation $S(x)_{\text {max }}=30$, shown as the dotted line), the calculated curve coincides with the 


\section{$(\mathrm{Ba}, \mathrm{Sr}) \mathrm{SO}_{4}$}
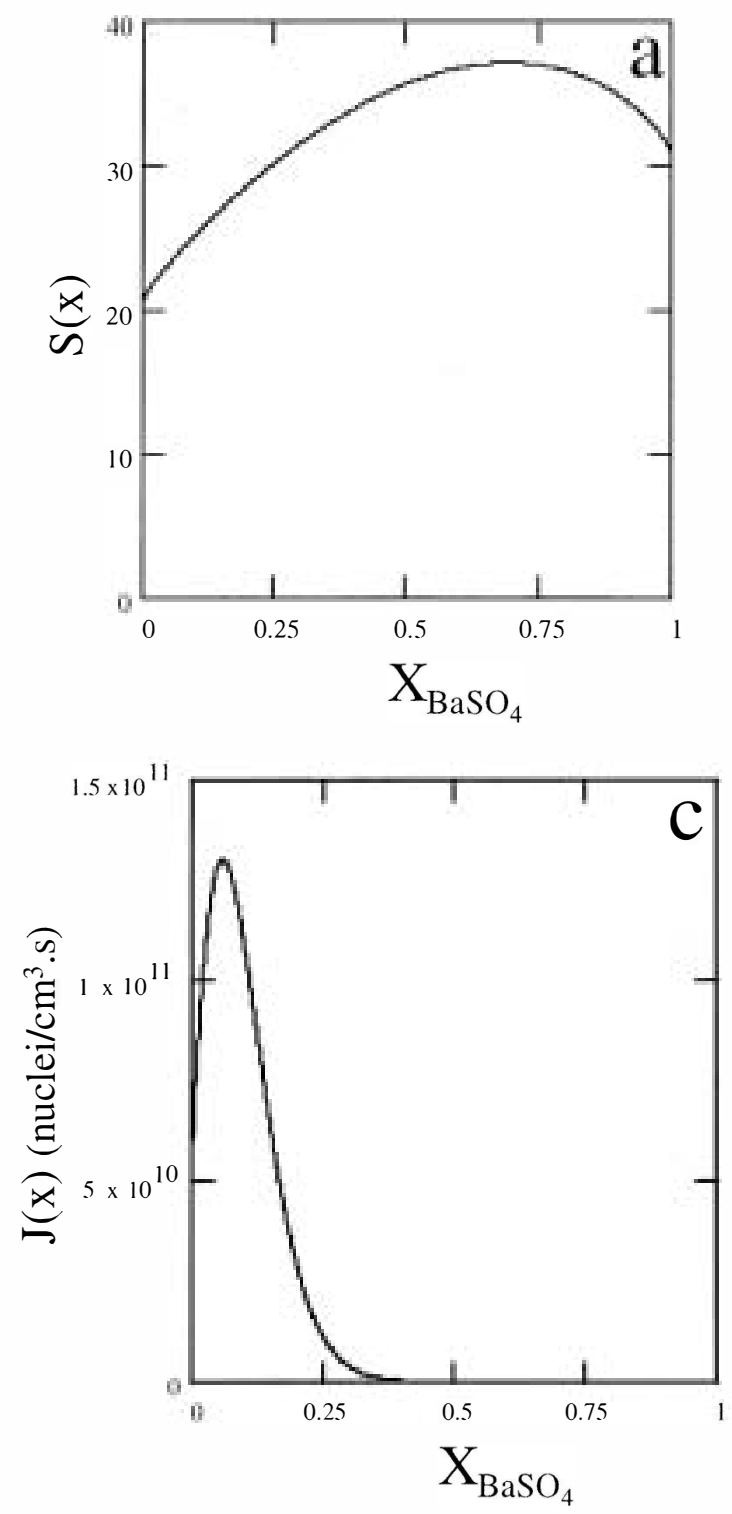

\section{$(\mathrm{Ba}, \mathrm{Sr}) \mathrm{CO}_{3}$}
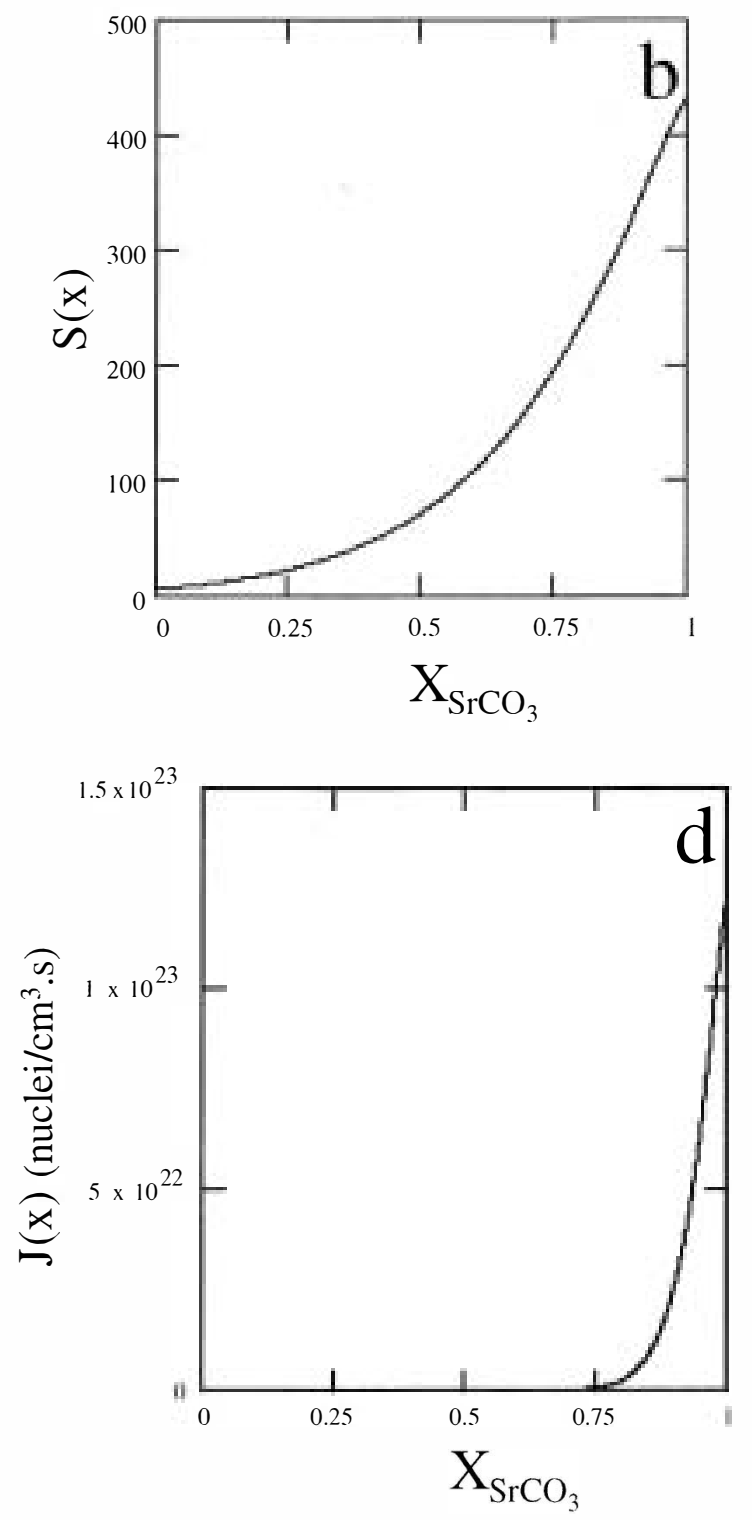

Fig. 1. Supersaturation and nucleation rate functions for the the $(\mathrm{Ba}, \mathrm{Sr}) \mathrm{SO}_{4}$ and $(\mathrm{Ba}, \mathrm{Sr}) \mathrm{CO}_{3}$ solid solutions. (a) Supersaturation function $S(x)$ calculated for the aqueous solution of composition $a\left(\mathrm{Sr}^{2+}\right)=a\left(\mathrm{SO}_{4}^{2-}\right)=0.01 \mathrm{~mol} / \mathrm{L}$ and $a\left(B a^{2+}\right)=0.00001 \mathrm{~mol} / \mathrm{L}$. (b) Supersaturation function $S(x)$ calculated for the aqueous solution of composition $a\left(\mathrm{Sr}^{2+}\right)=$ $a\left(\mathrm{CO}_{3}^{2-}\right)=0.01 \mathrm{~mol} / \mathrm{L}$ and $a\left(B a^{2+}\right)=0.00001 \mathrm{~mol} / \mathrm{L}$. (c) and (d) Nucleation rate functions, $J(x)$, for the solutions with the composition given in (a) and (b), respectively. In all plots the $\mathrm{X}_{\mathrm{Bas} \bullet 4}$ molar fraction in the ( $\left.\mathrm{Ba}, \mathrm{Sr}\right) \mathrm{SO}_{4}$ solid, and the $\mathrm{X}_{\mathrm{SrC} \bullet}$ molar fraction in the $(\mathrm{Ba}, \mathrm{Sr}) \mathrm{CO}_{3}$ solid have been represented in the abscissa.

Roozeboom curve obtained for thermodynamic equilibrium (solid line). By increasing the supersaturation with respect to the whole solid solution series, the kinetic Roozeboom diagram moves away from the equilibrium curve. The dashed line in Figure 3 a shows the Roozeboom diagram corresponding to an aqueous solution with a maximum supersaturation of $S(x)_{\max }=$ $10^{4}$. The same effect, but more evident, can also be observed in the $\mathrm{Ba}^{2+}-\mathrm{Sr}^{2+}-\mathrm{CO}_{3}^{2-}-\mathrm{H}_{2} \mathrm{O}$ system. Figure $3 \mathrm{~b}$ shows the equilibrium Roozeboom curve (solid line) and a curve calculated for a small departure from equilibrium in the system $S(x)_{\max }=$ 6 (dotted line). By increasing the supersaturation levels it is possible to obtain curves with progressively less curvature. The dashed curve shown in Figure $3 \mathrm{~b}$ was calculated for an aqueous solution with maximum supersaturation, $S(x)_{\max }=600$. When the kinetic Roozeboom plot is linear with slope 1, we are in the situation where no preferential incorporation of any ion into the solid solution occurs, i.e., the solid will have the same composition as the liquid from which it crystallised. 
Table 1. Parameters used to calculate $J(x)$. Interfacial free energies, $\sigma$, are in the range of those reviewed by Sangwal (1989). The interfacial free energy for $\mathrm{CdCO}_{3}$ was calculated from its solubility using the empirical expression by Söhnel (1982): $\sigma=34.8-17.8$ log $c_{0}\left(c_{0}=\right.$ equilibrum solubility). Pre-exponential factors were calculated using eq(10) with $\mathrm{D}=10^{-9} \mathrm{~m}^{2} \mathrm{~s}^{-1}$. The solubility products, $K_{s}$, were taken from: (a) Blount, 1977 ; (b) Reardon and Armstrong, 1987; (c) Smith and Martell, 1976; (d) Busenberg and Plummer, 1986; (e) Busenberg et al., 1984 (f) Plummer and Busenberg, 1987; (g) Stipp et al., 1993.

\begin{tabular}{lcccc}
\hline \hline Endmember & $\Omega\left(m^{3}\right)$ & $\sigma\left(J / m^{2}\right)$ & $\Gamma$ & $K_{s}$ \\
\hline $\mathrm{BaSO}_{4}$ & $8.6 \times 10^{-29}$ & 0.125 & $5.98 \times 10^{37}$ & $10^{-9.98(\mathrm{a})}$ \\
$\mathrm{SrSO}_{4}$ & $7.7 \times 10^{-29}$ & 0.097 & $7.18 \times 10^{37}$ & $10^{-6.63(\mathrm{~b})}$ \\
$\mathrm{BaCrO}_{4}$ & $9.3 \times 10^{-29}$ & 0.110 & $5.28 \times 10^{38}$ & $10^{-9.67(\mathrm{c})}$ \\
$\mathrm{BaCO}_{3}$ & $7.6 \times 10^{-29}$ & 0.100 & $7.33 \times 10^{37}$ & $10^{-8.56(\mathrm{~d})}$ \\
$\mathrm{SrCO}_{3}$ & $6.5 \times 10^{-29}$ & 0.130 & $9.52 \times 10^{37}$ & $10^{-9.27(\mathrm{e})}$ \\
$\mathrm{CaCO}_{3}$ & $6.1 \times 10^{-29}$ & 0.104 & $1.05 \times 10^{38}$ & $10^{-8.48(\mathrm{f})}$ \\
$\mathrm{CdCO}_{3}$ & $5.7 \times 10^{-29}$ & 0.142 & $1.19 \times 10^{38}$ & $10^{-12.1 \bullet(\mathrm{g})}$ \\
\hline
\end{tabular}

\subsection{Comparison Between Experimental and Calculated Roozeboom Diagrams}

The effect of non equilibrium on the composition of solid solution crystallising from aqueous solution has been demonstrated by Prieto et al., 1997. These authors obtained crystals of $(\mathrm{Ba}, \mathrm{Sr}) \mathrm{CO}_{3}, \mathrm{Ba}\left(\mathrm{SO}_{4}, \mathrm{CrO}_{4}\right),(\mathrm{Ba}, \mathrm{Sr}) \mathrm{SO}_{4}$ and $(\mathrm{Cd}, \mathrm{Ca}) \mathrm{CO}_{3}$ solid solutions by counterdiffusion of reactants through a column of silica gel. This method allows high supersaturation levels to be reached and by analysing both the interstitial aqueous solution of the gel at the nucleation time and the core of the crystals it is possible to determine the aqueous solution-solid solution compositional pairs at far from equilibrium conditions. By starting with mother solutions of different concentrations (different substituting ion ratios), Prieto et al., 1997 obtained aqueous solution-solid solution pairs for complete ranges of activity fractions of the ions in solution. Such compositional pairs can be plotted on Roozeboom diagrams to visualise the effect of non equilibrium on the distribution coefficients. In Table 2 nucleation data reported by Prieto et al., 1997 for the $(\mathrm{Ba}, \mathrm{Sr}) \mathrm{CO}_{3}, \mathrm{Ba}\left(\mathrm{SO}_{4}, \mathrm{CrO}_{4}\right),(\mathrm{Ba}, \mathrm{Sr}) \mathrm{SO}_{4}$ and $(\mathrm{Cd}, \mathrm{Ca}) \mathrm{CO}_{3}$ solid solutions are summarised. In the case of the $\mathrm{Ba}\left(\mathrm{SO}_{4}, \mathrm{CrO}_{4}\right)$ the solid compositions are those reported by Martín-Díaz (1997),
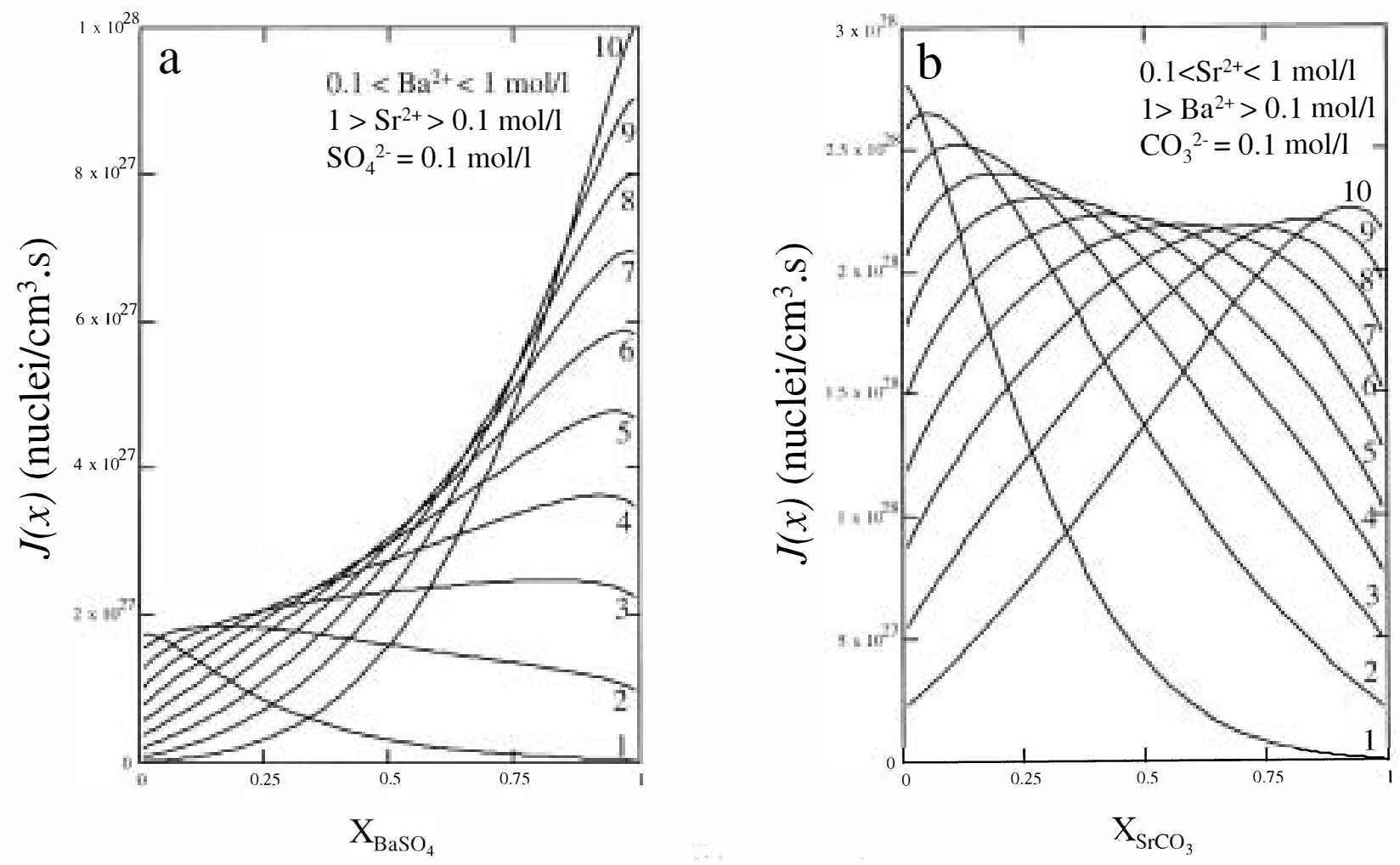

Fig. 2. Nucleation rate functions $J(x)$ for complete ranges of aqueous solution compositions. (a) $\mathrm{Ba}^{2+}-\mathrm{Sr}^{2+}-\mathrm{SO}_{4}^{2-}-\mathrm{H}_{2} \mathrm{O}$ system. Curve 1 was calculated for a solution with composition $\left[\mathrm{Ba}^{2+}\right]=0.1 \mathrm{~mol} / \mathrm{L} ;\left[\mathrm{Sr}^{2+}\right]=1 \mathrm{~mol} / \mathrm{L}$ and $\left[\mathrm{SO}_{4}^{2-}\right]=0.1$ $\mathrm{mol} / \mathrm{L}$. Curves 2 to 10 were obtained by increasing and decreasing at intervals of $0.1 \mathrm{~mol} / \mathrm{L}$ the $\mathrm{Ba}^{2+}$ and $\mathrm{Sr}^{2+}$ concentrations respectively. (b) $\mathrm{Ba}^{2+}-\mathrm{Sr}^{2+}-\mathrm{CO}_{3}^{2-}-\mathrm{H}_{2} \mathrm{O}$ system. Curve 1 was calculated for a solution with composition $\left[\mathrm{Sr}^{2+}\right]=0.1 \mathrm{~mol} / \mathrm{L}$; $\left[\mathrm{Ba}^{2+}\right]=1 \mathrm{~mol} / \mathrm{L}$ and $\left[\mathrm{CO}_{3}^{2-}\right]=0.1 \mathrm{~mol} / \mathrm{L}$. Curves 2 to 10 were obtained by increasing and decreasing at intervals of 0.1 $\mathrm{mol} / \mathrm{L}$ the $\mathrm{Sr}^{2+}$ and $\mathrm{Ba}^{2+}$ concentrations respectively. 


\section{$(\mathrm{Ba}, \mathrm{Sr}) \mathrm{SO}_{4}$}

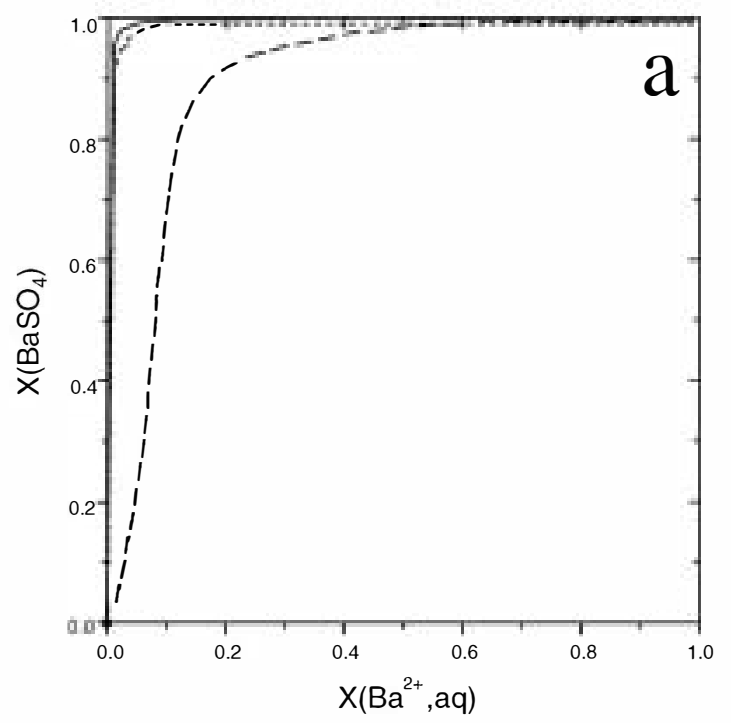

$(\mathrm{Ba}, \mathrm{Sr}) \mathrm{CO}_{3}$

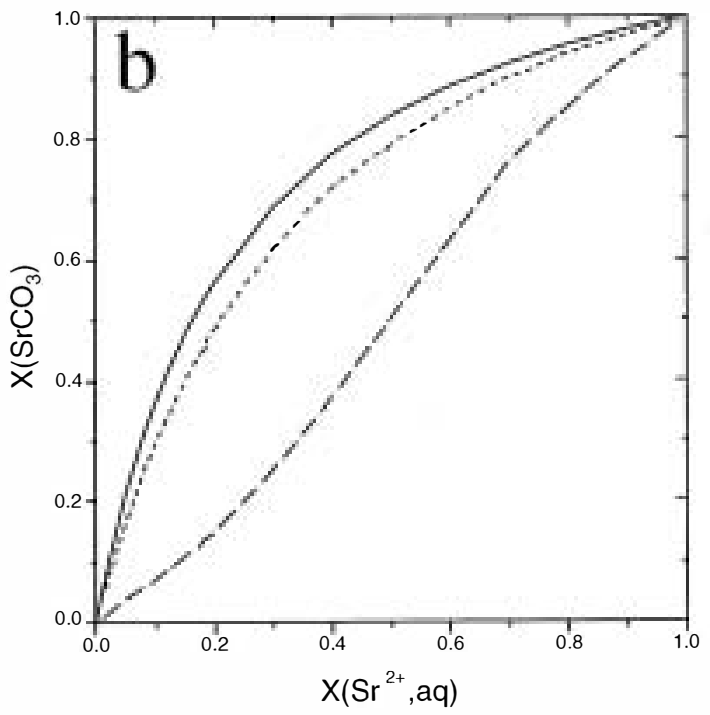

Fig. 3. Roozeboom diagrams for (a) $\mathrm{Ba}^{2+}-\mathrm{Sr}^{2+}-\mathrm{SO}_{4}^{2-}-\mathrm{H}_{2} \mathrm{O}$ and(b) $\mathrm{Ba}^{2+}-\mathrm{Sr}^{2+}-\mathrm{CO}_{3}^{2-}-\mathrm{H}_{2} \mathrm{O}$ systems. Roozeboom diagrams at thermodynamic equilibrium are represented by solid lines. Calculated Roozeboom diagrams close to equilibrium are shown as dotted lines and far from equilibrium as dashed lines.

which correspond to most recent chemical analyses and are of better quality (M. Prieto and A. Fernández-González, personal communication). Figure 4 shows the experimental aqueous solution-solid solution composition pairs (triangles) plotted on Roozeboom diagrams. As can be seen the experimental data do not lie on the Roozeboom diagram at equilibrium (solid lines)

We have applied the method for constructing Roozeboom diagrams described in section 3.2. to simulate the nucleation experimental data obtained for the SS-AS systems mentioned above. Calculations have been carried out with aqueous solution activities corresponding to the activity fractions given in Table 2 and using the supersaturation function equation (Eqn. 4). Once supersaturation functions were calculated (assuming that all solid solutions are ideal), the nucleation rate functions

Table 2. Nucleation data reported by Prieto et al., 1997 for gel experiments. The activity fractions of the ions in the intersititial aqueous solution at nucleation times were taken from Prieto et al., 1997 and Martín Díaz* (1997). The activity fractions for the solid correspond to the cores of the crystals. Calculated values in this work are also given.

\begin{tabular}{|c|c|c|c|c|c|c|c|}
\hline & $\mathrm{X}(\mathrm{Ba}, \mathrm{aq})$ & $\mathrm{X}\left(\mathrm{BaSO}_{4}\right)^{\exp }$ & $\mathrm{X}\left(\mathrm{BaSO}_{4}\right)^{\mathrm{calc}}$ & & $\mathrm{X}\left(\mathrm{SO}_{4}, \mathrm{aq}\right)$ & $\left.\mathrm{X}(\mathrm{BaSO})_{4}\right)^{\exp }$ & $\mathrm{X}\left(\mathrm{BaSO}_{4}\right)^{\mathrm{calc}}$ \\
\hline \multirow{11}{*}{$(\mathrm{Ba}, \mathrm{Sr}) \mathrm{SO}_{4}$} & 0.00 & 0.00 & 0 & \multirow{11}{*}{$\mathrm{Ba}\left(\mathrm{SO}_{4}, \mathrm{CrO}_{4}\right)^{*}$} & 0.00 & 0.00 & 0.00 \\
\hline & 0.17 & 0.64 & - & & 0.29 & 0.12 & 0.08 \\
\hline & 0.27 & 0.79 & 0.74 & & 0.33 & 0.17 & 0.09 \\
\hline & 0.42 & 0.87 & - & & 0.51 & 0.45 & 0.41 \\
\hline & 0.45 & 0.88 & - & & 0.62 & 0.73 & 0.8 \\
\hline & 0.46 & 0.90 & 0.87 & & 0.66 & 0.78 & 0.85 \\
\hline & 0.47 & 0.90 & 0.89 & & 1.00 & 1.00 & 1.00 \\
\hline & 0.47 & 0.91 & 0.91 & & $\mathrm{X}(\mathrm{Cd}, \mathrm{aq})$ & $\mathrm{X}\left(\mathrm{CdCO}_{3}\right)^{\exp }$ & $\mathrm{X}\left(\mathrm{CdCO}_{3}\right)^{\mathrm{calc}}$ \\
\hline & 0.49 & 0.89 & 0.91 & & 0.000 & 0.00 & 0.00 \\
\hline & 0.55 & 0.93 & 0.92 & & 0.010 & 0.20 & 0.5 \\
\hline & 0.64 & 0.94 & 0.96 & & 0.015 & 0.54 & 0.61 \\
\hline \multirow{12}{*}{$(\mathrm{Sr}, \mathrm{Ba}) \mathrm{CO}_{3}$} & 0.82 & 0.99 & 1 & \multirow{12}{*}{$(\mathrm{Cd}, \mathrm{Ca}) \mathrm{CO}_{3}$} & 0.022 & 0.63 & 0.67 \\
\hline & 1.00 & 1.00 & 1 & & 0.025 & 0.79 & 0.77 \\
\hline & $\mathrm{X}(\mathrm{Sr}, \mathrm{aq})$ & $\mathrm{X}\left(\mathrm{SrCO}_{3}\right)^{\exp }$ & $\mathrm{X}\left(\mathrm{SrCO}_{3}\right)^{\mathrm{calc}}$ & & 0.051 & 0.81 & 0.84 \\
\hline & 0.00 & 0.00 & 0 & & 0.082 & 0.82 & 0.85 \\
\hline & 0.06 & 0.08 & 0.03 & & 0.103 & 0.86 & 0.89 \\
\hline & 0.24 & 0.22 & 0.21 & & 0.133 & 0.89 & 0.92 \\
\hline & 0.30 & 0.33 & 0.21 & & 0.235 & 0.94 & 0.94 \\
\hline & 0.47 & 0.43 & 0.38 & & 0.481 & 0.96 & 0.98 \\
\hline & 0.66 & 0.62 & 0.59 & & 0.721 & 0.98 & 0.99 \\
\hline & 0.73 & 0.68 & 0.77 & & 1.000 & 1.00 & 1.00 \\
\hline & 0.87 & 0.86 & 0.86 & & & & \\
\hline & 1.00 & 1.00 & 1.00 & & & & \\
\hline
\end{tabular}



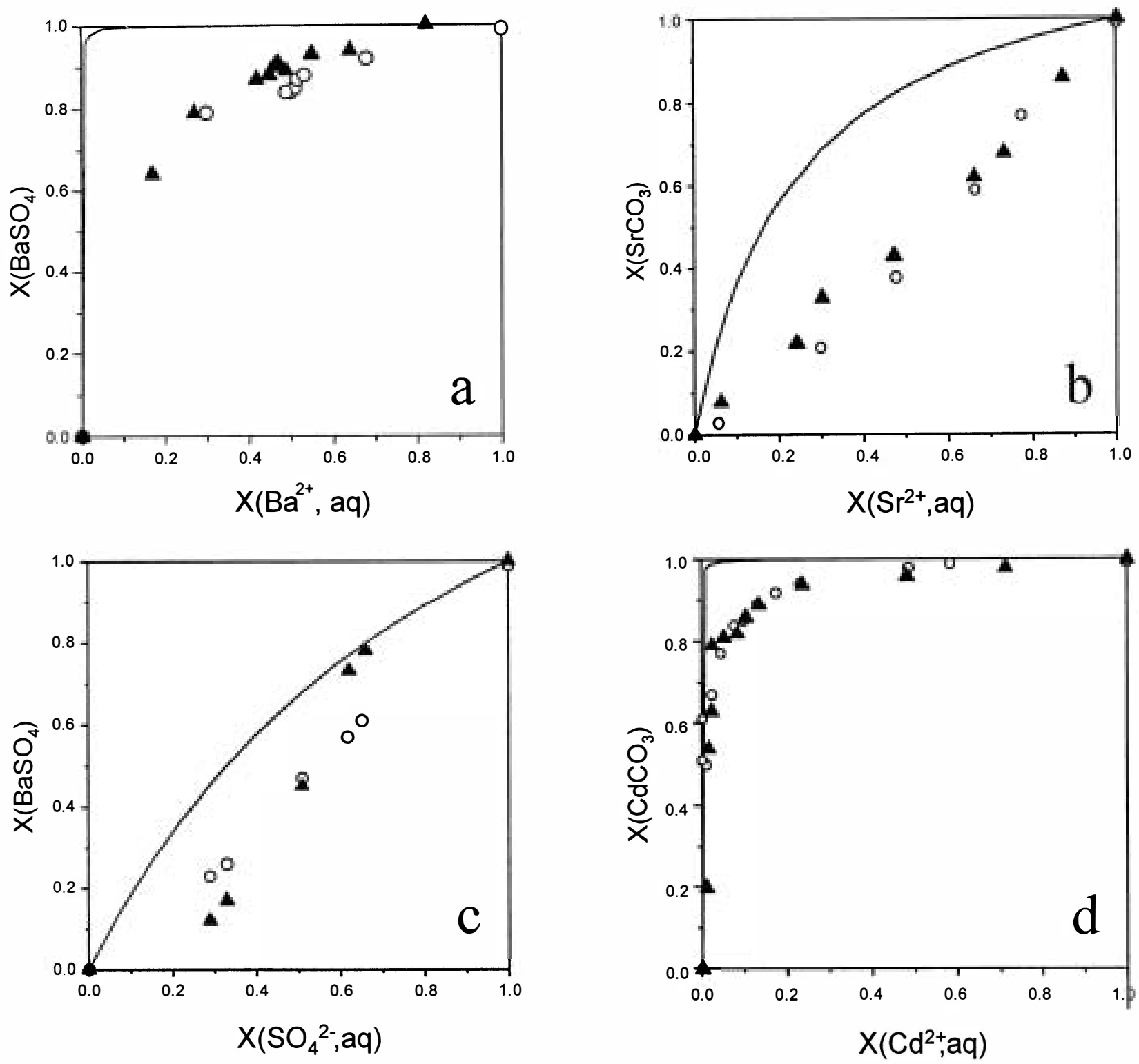

Fig. 4. Comparison between calculated and experimental Roozeboom diagrams at far from equilibrium conditions. (a) (Ba, Sr) $\mathrm{SO}_{4}-\mathrm{H}_{2} \mathrm{O}$; (b) (Ba, Sr) $\mathrm{CO}_{3}-\mathrm{H}_{2} \mathrm{O}$; (c) $\mathrm{Ba}\left(\mathrm{SO}_{4}, \mathrm{CrO}_{4}\right)-\mathrm{H}_{2} \mathrm{O}$ and (d) $(\mathrm{Cd}, \mathrm{Ca}) \mathrm{CO}_{3}-\mathrm{H}_{2} \mathrm{O}$. Calculated points have been plotted as open circles. Experimental data are represented by triangles and taken from Prieto et al., 1997 except those for the $\mathrm{Ba}\left(\mathrm{SO}_{4}, \mathrm{CrO}_{4}\right)-\mathrm{H}_{2} \mathrm{O}$ systems, which were taken from Martín-Díaz, 1997. The solid line on each diagram corresponds to the Roozeboom diagram at equilibrium.

were evaluated (Eqn. 2) and the solid solution composition for which the nucleation rate reached a maximum was obtained. The final step consisted of plotting the activity fraction of the aqueous solution against the molar fraction of the solid phase with the maximum nucleation rate. In Table 1 the parameters used to calculate $J(x)$ functions are shown. Since there is little agreement in the published values for the interfacial free energies of the endmembers, for our calculations we have chosen values which allow us to optimize the calculations (Sangwal, 1989). This optimisation was done using the equilibrium Roozeboom diagrams as a reference, i.e., the optimal interfacial free energy is the value for which the equilibrium Roozeboom diagrams can be reproduced when very low supersaturations are considered (close to thermodynamic equilibrium). The rest of parameters have been taken from the literature or obtained by simple calculations (as indicated in the text of Table 1)

Figure 4 shows the compositional pairs calculated (open circles) for the $(\mathrm{Ba}, \mathrm{Sr}) \mathrm{CO}_{3}-\mathrm{H}_{2} \mathrm{O}, \mathrm{Ba}\left(\mathrm{SO}_{4}, \mathrm{CrO}_{4}\right)-\mathrm{H}_{2} \mathrm{O}$, ( $\mathrm{Ba}, \mathrm{Sr}) \mathrm{SO}_{4}-\mathrm{H}_{2} \mathrm{O}$ and $(\mathrm{Cd}, \mathrm{Ca}) \mathrm{CO}_{3}-\mathrm{H}_{2} \mathrm{O}$ SS-AS systems. As can be observed in all cases the calculated data are in good agreement with the experimental ones. The effect of non equilibrium on the distribution coefficients for the systems studied can therefore be justified by considering its influence on the nucleation kinetics of solid solution compositions, i.e., the changes in the nucleation rate function. 


\section{CONCLUDING REMARKS}

From the model presented here we can make the following general conclusions:

1. In a SS-AS system the maximum supersaturation value and the maximum nucleation rate do not necessarily correspond to the same solid composition. For certain aqueous solution compositions these differences can be very important. More soluble compositions will be kinetically favoured (i.e., higher values of nucleation rate) and will tend to nucleate even though they are less supersaturated than less soluble compositions. This effect will be more important for solid solutions with large differences in the solubility products of the endmembers.

2. By considering the distribution of nucleation rates as a fumction of the solid solution compositions, $J(x)$, for a range of given aqueous solutions it is possible to calculate Roozeboom diagrams which reflect the effect of supersaturation on distribution coefficients, i.e., kinetic Roozeboom diagrams.

3. The results of our model are consistent with the general trend: higher departures from equilibrium correspond to Roozeboom diagrams with lower curvature.

4. The model has been demonstrated to be successful for explaining previous experimental data for the $(\mathbf{B a}, \mathrm{Sr}) \mathrm{CO}_{3}$ $\mathrm{H}_{2} \mathbf{\bullet}, \mathrm{Ba}\left(\mathrm{SO}_{4}, \mathrm{ClO}_{4}\right)-\mathrm{H}_{2} \mathbf{O},(\mathrm{Ba}, \mathrm{Sr}) \mathrm{SO}_{4}-\mathrm{H}_{2} \mathbf{O}$ and $(\mathrm{C}, \mathrm{Ca}) \mathrm{CO}_{3}-$ $\mathrm{H}_{2} \bigcirc$ systems (reported by Prieto et al., 1997).

5. Calculation of Roozeboom diagrams from the evaluation of $J(x)$ is a simple way of predicting actual distribution coefficients in SS-AS systems. In principle, this calculation requires knowledge of few parameters (interfacial free energy of the endmembers, solubility products and molar volume). However, the uncertainties in some starting parameters (e.g., interfacial free energy) can lead to erroneous predictions. In such cases the chosen starting parameters are those which fit the equilibrium Roozeboom diagrams.

6. The calculation of kinetic Roozeboom diagrams can be carried out for any SS-AS system and can be a very useful way of predicting and explaining actual distribution coefficients in industrial processes and geological environments.

Acknøwledgments-The authors thank A. Fernández-González for providing detailed information and comments on experimental data by Prieto et al., 1997. We thank the Deutsche Forschungsgemeinschaft (DFG) for financial support for this work. C.M. Pina acknowledges the receipt of a Marie Curie Fellowship from the European Commission. We also thank Dr. S. L. S. Stipp and an anonymous reviewer for very helpful comments.

Asseciate editer: E. J. Reardon

\section{REFERENCES}

Becker U., Fernández-González A., Prieto M. Harrison R., Putnis A. (2000). Direct calculation of thermodynamic properties of the barite/ celestite solid solution from molecular principles. Phys. Chem. Min. 27, 291-300.

Blount C. W. (1977) Barite solubilities and thermodynamic quantities up to $300^{\circ} \mathrm{C}$ and 1400 bars. Am. Mineral. 62, 942-957.

Busenberg E. and Plummer L. N. (1986) The solubility of $\mathrm{BaCO}_{3}$ (witherite) in $\mathrm{CO}_{2}-\mathrm{H}_{2} \mathrm{O}$ solutions between $\mathbf{0}$ and $\mathbf{9 0 ^ { \bullet }}$, an evaluation of the association constants of $\mathrm{BaHCO}_{3}^{+}$(aq) and $\mathrm{BaCO}_{3}^{\circ}$ (aq) between 5 and $80^{\circ} \mathrm{C}$, and preliminary evaluation of the thermodynamic properties of $\mathrm{Ba}^{2+}$. Geechim. Cesmechim. Acta. 50, 2225 2233.

Busenberg E., Plummer L. N. and Parker V. B. (1984) The solubility of strontianite $\mathrm{SrCO}_{3}$ in $\mathrm{CO}_{2}-\mathrm{H}_{2} \mathrm{O}$ solutions between 2 and $91^{\circ} \mathrm{C}$, the association constants of $\mathrm{SrHCO}_{3}^{+}$and $\mathrm{SrCO}_{3}^{*}$ (aq) between 5 and $80^{\circ} \mathrm{C}$, and an evaluation of the thermodynamic properties of $\mathrm{Sr}^{2+}$ (aq) and $\mathrm{SrCO}_{3}$ (cr) at $25^{\circ} \mathrm{C}$ and 1 atm total pressure. Geochim. Cesmechim. Acta. 48, 2021-2035.

Christoffersen J., Rostrup E. and Christoffersen, M. R. (1991) Relation between interfacial surface tension of electrolyte crystals in aqueous supension and their solubility; a simple derivation based on surface nucleation. J. Cryst. Growth. 113, 599-605.

Glynn P. D. and Reardon E. J. (1990) Solid-solution aqueous solution equilibria: thermodynamic theory and representation. Am. J. Sci. 290, 164-201

Hanor J. S. (1968) Frequency distribution of composition in the baritecelestite series. Am. Mineral. 53, 1215-1222.

Malinin S. D. And Urusov V. S. (1983) The experimental and theoretical data on isomorphism in the $(\mathrm{Ba}, \mathrm{Sr}) \mathrm{SO}_{4}$ system in relation to barite formation. Geekhimiya 9, 1324-1334

Martín Díaz R. (1997) Cristalización y determinación del diagrama de fases en el sistema $\mathrm{Ba}\left(\mathrm{SO}_{4}, \mathrm{CrO}_{4}\right)-\mathrm{H}_{2} \mathrm{O}$ mediante el método Lippmann-Madelung-Vegard. (in Spanish). Degree Thesis. (not published).

Nielsen A. E. (1964) Kinetics of Precipitation, Pergamon Press, Oxford and New York.

Nielsen A. E. and Sohnel O. (1971) Interfacial tensions electrolyte crystal-aqueous solution from nucleation data. J. Cryst. Growth. 11, 233-242.

Plummer L. N. and Busenberg E. (1987) Thermodynamics of the aragonite-strontianite solid solutions: Results from stoichiometric solubility at 25 and $76^{\circ} \mathrm{C}$. Geechim. Cosmechim. Acta. 51, 1393411.

Prieto M., Viedma C, López-Acevedo V., Martín-Vivaldi J.L. and López-Andrés, S. (1988) Mass Transfer and supersaturation in crystal growth in gels. J. Cryst. Growth. 92, 61-68.

Prieto M., Fernández-Díaz L. and López-Andrés S. (1991) Supersaturation evolution and first precipitate location in crystal growth in gels. J. Cryst. Growth. 98, 447-460

Prieto, M., Fernández-Díaz, L. and López-Andrés, S. (1994) Metastability in diffusing-reacting systems. J. Cryst. Growth. 108, 770-778.

Prieto M., Femández-González A., Putnis A. and Fernández-Díaz L. (1997) Nucleation, growth and zoning phenomena in crystallizing $(\mathrm{Ba}, \mathrm{Sr}) \mathrm{CO}_{3}, \mathrm{Ba}\left(\mathrm{SO}_{4}, \mathrm{CrO}_{4}\right),(\mathrm{Ba}, \mathrm{Sr}) \mathrm{SO}_{4}$, and $(\mathrm{Cd}, \mathrm{Ca}) \mathrm{CO}_{3}$ solid solutions from aqueous solutions. Geøchim. Cesmechim. Acta. 61, 3383-3397.

Putnis A. Prieto M. and Fernández-Díaz L. (1995) Fluid supersaturation and crystallisation in porous media. Geel. Mag. 132, 1-13.

Reardon E. J. and Armstrong D. K. (1987) Celestite $\left(\mathrm{SrSO}_{4}(\mathrm{~s})\right)$ solubility in water, sea water and $\mathrm{NaCl}$ solution. Geechim. Cosmechim. Acta. 51, 63-72.

Sangwal K. (1989) On the estimation of surface entropy factor, interfacial tension, dissolution enthalpy and metastable zone-width for substances cristallizing from solution. J. Cryst. Growth. 97, 393405.

Smith R. M. and Martell A. E. (1976) Critical Stability Constants. Vol. 4. Inorganic Complexes. Plenum.

Söhnel O. (1982) Electrolyte crystal-aqueous solution interfacial tensions from crystallisation data. J. Cryst. Growth. 57, 101-108.

Stipp S. L., Parks G. A., Nordstrom D. K. and Leckie J. O. (1993) Solubility-product constant and thermodynamic properties for synthetic otavite, $\mathrm{CdCO}_{3(\mathrm{~s})}$, and aqueous association constants for the $\mathrm{Cd}(\mathrm{II})-\mathrm{CO}_{2}-\mathrm{H}_{2} \mathrm{O}$ system. Geochim. Cosmechim. Acta. 57, 26992713.

Walton A. G. (1969) Nucleation in liquids and solutions. In Nucleation (ed. Zettlemoyer), pp. 225-307. New York: Marcel Dekker Inc. 